\title{
The Value Orientation and Ultimate Goal of Education
}

\author{
Jia-Qi WU ${ }^{1, a}$, Ai-Qun YU ${ }^{2, b,{ }^{*}, D i n g-X i a n g ~ L I U ~}{ }^{3, c}$ \\ 1,2,3 City College of Science and Technology, Chongqing University, Chongqing, China \\ aM18875136336@163.com, bohym0202@163.com, 'liudingxiang@sina.com
}

Keywords: value orientation, Ultimate Goal, philosophy of education.

\begin{abstract}
The theme of educational philosophy has not changed. Education can never forget and neglect the existence of human life. Because of its unique, rich and diverse human life, education has become fascinating, entertaining, and difficult, and there is no end to any exploration of education. All life can't be replaced by another life, life has uniqueness, reverence for life is the starting point of education ethics, education is also the value of dependence. Education is life's education, school is life's school.
\end{abstract}

\section{Introduction}

The history of philosophy of education has been in existence for more than 150 years since the publication of the Philosophy of Education in 1884 by J. K. Rosenkcranz. At present, the focus of educational philosophy has shifted to thematic discourses such as democracy, freedom, fairness, The relationship between educational modernization and postmodernism, in short, the historical issues and modern topics that need to be studied in educational philosophy are numerous. But, however, no matter at what the times, I think the value orientation and the ultimate goal of education are the most important and basic topics.

\section{The primary meaning of education}

Concerned about life, respect for life is the primary meaning of education. Does philosophy of education need a new theme? I do not think it necessary, because the theme of educational philosophy has not changed. Educators and educated people exist as individuals who cannot be replaced by either one. Education always points to each individual. No matter whether the impartation of knowledge or the opening of wisdom is ultimately to point out or moisturize life, that is, to establish oneself and accomplish human life.

Education can never forget and neglect the existence of human life. Because of its unique, rich and diverse, education has become fascinating, entertaining, and difficult, and there is no end to any educational exploration. Therefore, all educational behaviors need to be self-questioning and need to examine the value. Only because education and recognition of people truly become human education can schools become human schools. Precisely because it points to a specific person, life education becomes both urgent and probable. It is essentially intelligent and reflective. It focuses on practice and is constantly generating more and more 
life, Education is always in the path of life.

\section{The value rationality and instrumental rationality}

What happened now? The current changes are the times. Once the technology has changed, the methods of education, the content of education, the means of education, the mode of teaching and so forth will have to change accordingly. However, the value orientation and the ideal goal of education will never change.

Before the nineteenth century, education was in fact a handicraft apprenticeship, whether it be an oriental private school or a western tutor. However, with the increase in subjects and the need for a basic education workforce, there has been a so-called education system called K-12 (that is, our ordinary primary and secondary schools in Asia).The standard education mode of all countries in the modern world is just a few basic elements that we already consider natural: going to the school building at seven or eight in the morning, listening to lectures in the course of 40-60 minutes, in which teachers are responsible for speaking, Students are responsible for listening; interspersed with lunch and physical lessons in class.

Under the confines of a standardized curriculum, the vast and immense range of human thought that has existed has been artificially cut into pieces, pieces of manageable parts, and so-called disciplines. Similarly, the original concept of flowing, blending, mastery is divided into a separate unit of the curriculum. This classroom teaching model was first implemented by Prussian people in the 18th century. At that time, the Prussian did not educate students to think independently, but rather to produce a large quantity of loyal and manageable nationals. The values they have learned in school allow them to submit to the authority of their parents, teachers and churches and, of course, eventually obey the king.

Of course, the Prussian system of education was innovative in many aspects at the time. Such an education system has given tens of thousands of people a middle class, which has provided the vital driving force for Germany to become an industrial power. Based on the prevailing technological level, the most economical way to achieve the goal of education for all in the Kingdom of Prussia might be to adopt the Prussian system of education. However, the system prevented students from conducting more in-depth inquiry and did no good to their ability to think independently. However, in the nineteenth century, a high level of logical creativity in creativity might not be as important as the ideological obedience of command and action in mastering basic skills.

In the first half of the nineteenth century, the United States basically copied Prussia's education system. Just as in Prussia, this move can vigorously promote the construction of the middle class and enable them to obtain a job in the thriving industrial sector. In addition to the United States, this system was also followed in the nineteenth century by other European countries and extended to other countries outside of Europe and the United States. However, the current economic situation no longer requires a compliant and disciplined working class. On the contrary, it demands more and more workers' reading ability, math literacy and cultural heritage.

In East Asian countries, university entrance exams are always mixed with their 
longstanding tradition of imperial examination. In ancient society, there was not much demand for creativity, so the imperial examination system was a very good one. It completed the selection of social managers with minimal conflict and completed the establishment of a criterion of substituting intelligence for the door. The goal of college entrance exams is to choose the educators who are more malleable and aspiring to take the next step. Such talent is like liquid glass taken out of the melting furnace, which can be stretched and stretched so that its plasticity is very strong. Have succeeded in the examinations, they will have to be like on the kiln porcelain glaze, and can be used immediately, but if you do change, rupture is not scratched. but if you make any changes, they are not broken or scratched. In addition, the exam is a very limited use of tools. Ancient imperial examination on the omission of talent is well known. The test is difficult to measure the candidate's interest, ambition, imagination and practical ability.

Even knowledge learned in the best high school is negligible compared to college. Take liberal arts as an example. Compared with the required bibliographies of several history departments of the university, which one has a large amount of information in the history textbooks that need to be read repeatedly? As for math, calculus in high school has not been well learned even in high school mathematics. In 1900 all mathematics can be stuffed into 1,000 books, and by the year 2000 it already takes 100,000 books.

There is a popular ten thousand hours theory, seems to be a theoretical support for repeated practice. This discussion is more about activities of lower cognitive complexity such as chess, piano, basketball, taxi driving, spelling. However, it is hard to find enough evidence for activities with high cognitive complexity, such as creation and management. In fact, this point can instead be used to illustrate why the training of such violin-playing techniques has been modest in the West and flourishing in East Asian countries.

The U.S. education system uses double insurance to discourage students from over-consuming their exams. First, the SAT score is only one of the factors to be taken into consideration. It is unwise to over-emphasize the SAT. Second, the SAT has annual 6 times apply for the opportunity. In China, the education system doubles the way students waste their youth. First, the entrance exam scores are the decisive factor for admissions. Second, the examinations are conducted once a year.

Today's world needs lifelong learners who are creative, curious and self-directed and who are empowered to put forth new ideas and put them into practice. Unfortunately, the goals of the Prussian school of education are exactly the opposite of what society needs. Today's education completely ignores the extraordinary wonderful diversity and subtle differences among people, and it is these diversity and subtle differences that make people different in intelligence, imagination and talent.

The educational system in East Asia is rather specific, often being appreciated by outsiders and criticized by insiders.

Both China and South Korea are famous for their extreme tentativeness and academicism. Almost all South Korean children attend the cram school. In 2009, the gross profit of the Korean cram school was about 7.3 billion U.S. dollars, more than the profit of Samsung 
Electronics. In 2012, the OECD conducted the International Student Assessment Program, which ranks the first Korean student in mathematics and reading programs among all member states. However, this achievement was achieved at a fairly low level of efficiency. Some commented: "These children have doubled their efforts and doubled their spending.

The content of education has four components: knowledge, law, ethics and common sense which refers to an all-encompassing message that is different from the content of the school curriculum. There are three channels of education: school, society and family. Learning of knowledge and law relies heavily on schools, morals and common sense to learn mainly from society and family. So if 10 years ago the two channels of society and family did not work well, education would fail. However, in the Internet era, the educational role of society can be largely accomplished by the Internet. So parents who try to isolate their children from the Internet are likely to turn their children into idiots.

Due to the lack of a correct understanding and grasping of the features in today's economic times and the information age, education has deviated from the value rationality of instrumental rationality, which has brought about many educational problems. Therefore, it is more necessary to reiterate and clarify value rationality at present, emphasizing the role of value rationing in guiding instrumental rationality.

\section{Life education}

First of all, life education is the fulfillment of possibly healthier life. For every living individual, there is the possibility of a more sound development, and every living individual inherently contains this more sound possibility. Life-style education is to cultivate people's cherished love for life, to let everyone have a more dignified sense of life, and guide people to look forward to a better future.

Second, life education is a natural education that follows the life of the people. Life education is to cultivate the "inner and true strength" that belongs to him and to be irreplaceable in his natural endowment and has his uniqueness, and should not expect anything about the abilities that one does not exist in his life. A good education is to follow the good ends of the people and give people the potential to develop as much as possible to guide people from the natural state to the proper state. The ultimate goal of education is self-improvement of human morality, self-responsibility of the soul, self-improvement of personality and self-transcendence of the realm. All this, of course, must be done in a natural and appropriate manner. Life-oriented education also emphasizes the method, but emphasizes that the method should follow the humanity and the method should target the individual of life. In this sense, the so-called method must be open, agile and individual. It can also be said that such a wisdom of education must come from teachers' in-depth reflection on their work. The wisdom of education also comes from the teacher's responsibility, from his long-lasting and focused education.

Third, life education is personalized education. It affirms human nature, affirms the uniqueness of human beings, and finds the best breakthrough in everyone. Behind emphasizing personality, in fact, means that education needs sincere respect for the different 
characteristics of people. As a result of such respect being implemented in specific educational activities, it can be seen that education is indeed a difficult, laborious and complicated task. So it can only be "slow" in its own right. Eager and concise comments can make education rough, blunt and arbitrary, and immediate education is often the reactionary reaction to education. Therefore, patience, tolerance, understanding and fulfillment of every life are, in fact, the most basic positions that education should have.

Fourth, life education is the education of human's spiritual consciousness. It is not a simple teaching strategy and method, but spiritual consciousness, the most important is the meaning of life consciousness. People from the chaos, totally unaware of the state gradually see the direction of life, see the possibility of life, to see where the pursuit of the goal. The second level is where we know the value of our lives, and we still need such a kind of awakening. Another important thing is that on our journey to life we strive to truly make ourselves a unique person - a true teacher. As a student and teacher, we educate ourselves, ourselves and continue to enrich ourselves - - Fewer desires and fetters make their work a source of spiritual need and happiness.

Fifth, life education is a model education. Life education is based on the feeling of the soul where its charm lies. Therefore, its dominant approach lies not in logic or truth, but in achieving mental enlightenment through the intuition of the model. Model education is to face life, face the classic. The so-called face-to-face life is to use his own most willing way to personally experience the feelings of life say it. The so-called face-to-face classic is to directly read classic works at all times and in all countries. Reading these works is to follow one template after another and follow the living souls who provide these templates. The face-reading is speechless, but it is divine, and the process of divine fulfillment is the process of accepting the model education. This face-to-face life, face the classic education is the educator's life is always the presence of education, in other words, is a life-oriented education.

\section{The ultimate goal of education}

Life-oriented education is individualized education, and always points to the never-ending and forever-enduring individual of life. It has always been the fundamental purpose of perfecting every person who is sound and full of personality. Life-oriented education shows true goodwill for all life, obeying destiny, revenging nature, and viewing human as members of all living beings. It endeavors to cultivate the sensitivity to life, paying attention to the value of all life, affirming the meaning of all life, sympathy, compassion and love.

Life-oriented education takes the value of all life as its guide and upholds the lofty ideals of truth, kindness and beauty of education so that education bathes in the glorious humanity. It always pays attention to the difference of life and endeavors to accomplish the development goals that are different for all life.

Life-oriented education maintains and respects human dignity, treats the difference between culture and belief with a tolerant and appreciative attitude, and maintains and advocates human's freedom of choice and self-fulfillment.

Life-oriented education has always believed in people and always believed in the meaning 
of life. It has always believed that education can continuously overcome the ignorance, crudeness, narrowness, vulgarity, and move toward lightness, kindness, vastness, harmony and education in a humanistic way, which eventually won the liberation.

Life-oriented education treats everyone as the origin of ideas and creativity, treating everyone as a center of concentration of intellect and inspiration. The way to accomplish life education - starting from the meaning of believing every life, starting from perfecting each life development, starting from paying attention to, respecting and treating every student; starting from improving the way of evaluating students and starting from improving teaching strategies, Starting with improving ways of dealing with students and starting with improving the quality of self-life.

Life-oriented education is an idea that can't be done but work hard for it. It is a affirmation of a beautiful future for our people. Life-oriented education makes us a critically-built builder.

In short, the forgetfulness of life is the greatest tragedy of education, ignoring life is the biggest misconduct and misfortune in education. All life is more sacred than any possibility of knowledge, rule, discipline, even honor, promised future development and happiness. Life is both mysterious and can never be exhausted. Life is always "now" and "the present". It is the basis of all the well-being of our body. Life makes education possible and enriches and incredible.

All life can't be replaced by another life, life is unique. Awe is the ethical starting point of education and the value of education. Education is life's education, school is life's school.

\section{References}

[1] Huang Kejian, "Outline of Humanities," contained "philosophy" 1997 the ninth period.

[2] Zhang Wenzhi, "Education, Making Life Live - Zhang Wenzhi Talks on Life Education", "China Teachers Daily", "Depth Report" Section June 20, 2007.

[3] Education in the Perspective of Philosophy and Ideology, Gerald L. Gutek, Main Translator Chen Xiaotian Beijing Normal University Academic Press, January 2008.

[4] Nettleship, Richard L, The Theory of Education in the Republic of Plato. New York: Teachers College Press, Columbia University, 1968.

[5] http://inews.ifeng.com/51216701/news.shtml?ch=qq1\&back\&back\&back.

[6] Nobel Prize Laureate Reflections: Education in East Asia Wastes Too Much Life. 